\section{Três olhares, um só foco: a sociologia na Universidade de Brasília*}

Recebido: 09.11.16

Aprovado: 23.01.17

\author{
Maria Francisca Pinheiro Coelho, \\ Lourdes M. Bandeira \\ \& Mariza Veloso**
}

\section{Introdução}

A

história do Departamento de Sociologia da Universidade de Brasília pode ser reconstruída com base em três eixos narrativos: (i) o lugar das ciências sociais, no interior delas a sociologia, no projeto de criação de uma universidade pública na nova capital do país - Brasília. A Universidade de Brasília, vinculada à Fundação Universidade de Brasília, teve como seu primeiro reitor o antropólogo Darcy Ribeiro; (ii) a constituição de um corpus acadêmico voltado para as mudanças sociais. As disciplinas temáticas e os professores buscavam compreender as tensões vividas em um cenário político que anunciava, por um lado, a persistência de comandos tradicionais e, por outro, a existência de uma sociedade civil sintonizada com um projeto de mudanças. Atuar neste cenário era o desafio da sociologia na UnB; e, por fim, (iii) a relação entre Brasília e o ethos de produção da sociologia, os compromissos e a atuação das futuras gerações.

A direção das mudanças no país orientava o pensamento de Darcy Ribeiro:

O Brasil não pode passar sem uma universidade que tenha o inteiro domínio do saber humano e que o cultive não como um ato de fruição erudita ou de vaidade acadêmica, mas com o objetivo de, montada nesse saber, pensar o Brasil como um problema. Esta é a tarefa da Universidade de Brasília (Ribeiro, 1986a: 5).

Mais de cinco décadas se passaram, sem que a UnB e a sociologia perdessem os vínculos com o projeto inovador da Universidade. Em 2014, quando da decisão do Instituto de Ciências Sociais de se transferir do centro do Minhocão - como é chamado o Instituto Central de Ciências (ICC), principal prédio da UnB e agregador de seu patrimônio histórico e acadêmico - para um novo e moderno edifício, a professora Mariza Veloso foi voto vencido:

Como podemos abandonar o lugar primordial reservado às ciências sociais no coração do ICC e que resultou de uma distinção do papel central dessas ciências no projeto fundador da UnB?

\footnotetext{
* As autoras do texto ingressaram na UnB nos anos de 1970. Mariza Veloso na graduação de ciências sociais, em 1974, Lourdes M. Bandeira e Maria Francisca Pinheiro Coelho na pós-graduação em sociologia, em 1975. Muitos dos registros, relatos e memórias aqui apresentados se confundem com a própria história

da instituição. O mestrado de sociologia foi criado em 1970 e o doutorado em 1983. Em 2016, a pós-graduação de sociologia completou 46 anos e a Revista Sociedade e Estado, 30 anos.

** Maria Francisca Pinheiro Coelho é professora titular do Departamento de Sociologia da Universidade de Brasília. Lourdes M. Bandeira é professora titular do Departamento de Sociologia da Universidade de Brasília. Mariza Veloso é professora associada III do Departamento de Sociologia da Universidade de Brasília.
} 
Estudiosa do patrimônio histórico do Brasil e do projeto original da UnB, Veloso ressalta a importância das ciências sociais na concepção acadêmica da Universidade. Recorda que a decisão de situar as ciências sociais no coração do ICC não foi aleatória, mas para iluminar as ideias e os rumos a serem adotados pela Universidade:

A centralidade das ciências sociais no projeto acadêmico original da UnB levou a que essas ocupassem o lugar tradicional da filosofia, assumindo então o protagonismo para viabilizar a produção de conhecimento empírico e teórico sobre a realidade brasileira. Por esta razão, deveriam constar do currículo básico dos mais diferentes cursos da UnB. As ciências sociais fizeram assim parte das inovações e utopias inerentes ao próprio projeto de criação da UnB.

O saudosismo do voto da professora tinha uma base concreta que pode ser comprovada ainda hoje pela missão atribuída à sociologia de integrar o currículo dos mais diversos cursos, por meio da oferta da disciplina obrigatória de Introdução à sociologia. As ciências sociais deveriam integrar as diversas áreas do conhecimento, como fora previsto no desenho pedagógico proposto pelos fundadores da UnB. Em sua arquitetura original, o Minhocão, com seus mil metros de extensão, congregaria as principais áreas do conhecimento, onde estudantes não apenas circulariam, mas teriam um lugar de intensa convivência.

\section{As irmãs siamesas:}

\section{as ciências sociais e a UnB}

De algum modo, a história das ciências sociais na UnB se confunde com a história da instituição. A Universidade de Brasília foi fundada em 21 de abril de 1962, no espírito de mudanças e utopias da nova capital. A UnB fazia parte dos ideais então hegemônicos da intelectualidade brasileira, que tinha como pressupostos a universalidade do conhecimento, o intenso intercâmbio internacional e a certeza de que o sonho de uma sociedade mais justa estaria próximo. Segundo Darcy Ribeiro,

A UnB é a ambição mais alta da inteligência brasileira, este é o nosso sonho maior, esta é a utopia de quem entre nós tem cabeça para pensar este país e senti-lo com o coração [...]. Agora ela renasce e renasce porque o Brasil renasceu em liberdade (Ribeiro, 1986b: 6).

Ana Maria Costa, Deis Siqueira e Lourdes Maria Bandeira (1992: 3) enfatizam o papel do Instituto Central de Ciências no projeto da Universidade de Brasília: 
O Instituto Central de Ciências (ICC) foi pensado não apenas para congregar as ciências humanas, biológicas e exatas, mas os/as estudantes, os/as funcionários/as, professores/as e pesquisadores/ as, enfim, os/as passageiros/as daquela nova experiência científico-cultural. Nova porque integra e integradora, de estudantes de várias áreas do conhecimento, compartilhando espaço, ideia e ideais, cursos, equipamentos, vida, cultura, lazer e cotidiano, simultaneamente. Portanto, a possibilidade de construção de uma outra "universalidade" (Costa, Siqueira \& Bandeira, 1992: 3).

O tempo universitário na UnB era vivido não como uma cadeia curricular a ser cumprida, mas pela busca do conhecimento, ao mesmo tempo em que a formação da cidadania, os contados humanos, a criatividade e o lúdico eram a simbiose que matizava aquele cotidiano. Com o golpe militar, em 1964, a UnB sofreu várias intervenções. Contaram-se quatro intervenções principais na vida institucional da recém-inaugurada universidade: em 1964, durante o golpe, com a invasão da universidade por tropas militares; em 1965, com a expulsão de 13 professores, que resultou no pedido de demissão de mais de 200 professores; em 1968, no segundo semestre, devido à mobilização estudantil, quando um aluno foi baleado; e em 1977, em decorrência da greve geral dos estudantes pela criação de entidades estudantis livres.

Os anos de 1976 e 1977 foram de intensa mobilização estudantil na UnB, motivada pela defesa de eleições livres para as entidades estudantis. Em 20 de maio de 1976, nos últimos dias da gestão do reitor Amadeu Cury, este cancelou as eleições estudantis para o Diretório Universitário, alegando que a campanha continha ofensas ao governo e à universidade. Cinco dias depois, seu vice-reitor, José Carlos de Almeida Azevedo, foi nomeado reitor.

Na gestão de Azevedo, intensificou-se a repressão às mobilizações estudantis. Em julho de 1976, realizou-se na UnB a XXVIII Reunião Anual da Sociedade Brasileira para o Progresso da Ciência (SBPC), momento de grande repercussão no cenário das lutas pelas liberdades e de resistência ao regime militar.

As mobilizações na UnB continuaram em 1977, com suspensões e expulsões de estudantes. Em 3 de maio, foi deflagrada uma greve geral dos estudantes, ampliando-se para a pós-graduação. No dia 3 de junho, a Polícia Militar invadiu a UnB e permaneceu no campus até novembro. Apesar do recesso decretado pelo reitor para o mês de junho, a greve recomeçou logo após a volta do recesso. Com a retomada do movimento, em agosto, novas prisões foram efetivadas:

Ao fim do grande recesso, o saldo da repressão contabilizava os seguintes números: 9 estudantes cumpriram 30 dias de cadeia, 
cerca de 80 foram presos por 2 dias, mais de 200 foram intimados a depor, 14 estavam indiciados na Lei de Segurança Nacional, 30 estavam expulsos e 34 suspensos das atividades acadêmicas. Somavam-se, a isso, as 16 punições de 19 de maio, as 7 expulsões e 34 prisões de 1976 (Ramaiana Ribeiro, 2009: 160).

Um dos 30 estudantes expulsos da UnB era aluno da pós-graduação de sociologia. No período da greve, foi criada a Associação de Docentes da UnB, a ADUnB. No dia primeiro de agosto de 1977, 150 dos 730 professores da UnB assinaram a Ata de Fundação da Associação e divulgaram uma nota dirigida ao reitor José Carlos de Azevedo que reivindicava a imediata retirada dos policiais do campus. Passados três dias, foram realizadas mais de 200 prisões no campus. Pela manhã, os estudantes estavam em uma assembleia geral no Ceubinho, como é chamada a entrada norte do ICC, quando foram cercados pela polícia, presos e levados em camburões. Entre os presos estavam filhos de ministros, de parlamentares e de altos funcionários da República.

O clima na UnB era de guerra. Policiais mandavam alunos para as salas de aulas ou ficavam na porta das salas aguardando os alunos. Muitos professores não ministraram as aulas. Assim, o ano de 1977 chega ao fim com os estudantes mobilizados e sem que a greve seja formalmente decretada como terminada.

Na década de 1980, com a transição política do país, a UnB também fez sua transição democrática com a escolha, em 1984, do primeiro reitor pelas eleições diretas, o professor doutor em economia Cristovam Buarque. Encerrava-se assim um ciclo e iniciava-se outro, com novos desafios e perspectivas.

As respostas da UnB às frequentes intervenções militares fortaleceram o perfil de vanguarda da instituição no conjunto das universidades públicas federais e de seus cursos de ciências sociais. Apenas para citar alguns exemplos da marca proativa da UnB, pode-se listar algumas ações. O primeiro Diretório Central dos Estudantes Livre do país - após a extinção da União Nacional dos Estudantes (UNE) e dos diretórios estudantis, em 1968, entidades que, de certa forma, mantinham-se vinculadas à estrutura do Estado - foi criado na UnB, como conquista da greve dos estudantes em 1977. A ADUnB foi uma das primeiras associações fundadas nas universidades federais. Até então, os servidores federais não podiam ter associações nem sindicatos. Foi também em Brasília que se construiu o primeiro sindicato dos servidores públicos federais. As primeiras reuniões dos professores da UnB para a criação de sua associação foram realizadas às escondidas nas catacumbas - como são chamadas as salas que ficam no subsolo do Minhocão. Registra-se também que no regime militar e nos primeiros anos da abertura política, a UnB sediou encontros 
nacionais emblemáticos: como o da SBPC, em 1976; o da Associação Brasileira de Antropologia (ABA), em 1984; e o da Sociedade Brasileira de Sociologia (SBS), em 1986

A ousadia dos fundadores da UnB de criarem a Fundação Universidade de Brasília como instituição autônoma no conjunto das universidades públicas federais e a capacidade de resistência da instituição às constantes intervenções durante o regime militar são suas marcas indeléveis. A UnB foi criada como fundação a fim de libertá-la da opressão que o burocratismo ministerial exercia sobre as universidades públicas federais. A UnB deveria reger a si própria, livre e responsavelmente, não como empresa, mas como serviço público e autônomo.

Anos depois, já na década de 1990, e com a marca de uma tendência sindicalista uniformizadora da estrutura das instituições de ensino públicas federais, houve uma reestruturação e unificação das universidades federais com a aprovação da isonomia de carreira e salarial. Com essas mudanças, a UnB perdeu sua autonomia, nivelando-se ao conjunto das universidades federais. Esse processo resultou de uma reivindicação do próprio movimento docente nacional, o que levou à descaracterização da UnB como fundação. Com a isonomia, independentemente do nível de vida dos estados e das regiões, houve uma unificação da carreira e dos salários dos professores das universidades públicas federais.

A estrutura e a organização das ciências sociais constituem importante chave para a compreensão da trajetória da sociologia na UnB. Por isso, retomar algumas datas parece ser fundamental. O curso de ciências sociais foi criado no mesmo ano de fundação da UnB, 1962, mas foi muito atingido e desestruturado com as intervenções e demissões ocorridas. Em 1969, houve um processo de reestruturação do curso com a vinda do antropólogo Roque de Barros Laraia:

A UnB começou o seu processo de renascimento, abalada ainda pela crise política de 1965, quando perdeu a maior parte de seus professores competentes. Foi em 1969 que cheguei em Brasília com o encargo de extinguir o Departamento de Ciência Política e o de Antropologia e Sociologia e formar o novo Departamento de Ciências Sociais (Laraia, 1995: 17).

Quando o professor Roque Laraia chegou na UnB, o Instituto de Ciências Humanas possuía os seguintes departamentos: Antropologia e Sociologia, Ciência Política, FiIosofia e História e, por fim, Economia. Existiam os cursos de graduação em filosofia, história e economia. A geografia, então vinculada às geociências, passou a integrar as ciências humanas. 
1. Laraia, 2015. Entrevista concedida à Maria Francisca Pinheiro Coelho, no Departamento de Antropologia, na Universidade de Brasília, em 12 de junho de 2015.
Desde o início, o professor Roque Laraia teve a certeza de que o curso de ciências sociais dependia majoritariamente da sociologia, por isso o grupo de sociólogos contratados era bem maior do que o de antropólogos. Os novos professores admitidos vieram principalmente de Minas Gerais e poucos do Rio de Janeiro, como o próprio professor Roque Laraia e o professor Júlio César Melatti, provenientes do Museu Nacional da Universidade Federal do Rio de Janeiro.

Quando decidiu vir para Brasília, o professor Roque Laraia convidou alguns colegas do Rio, mas, naquelas circunstâncias, apenas o professor Melatti aceitou:

O salário em Brasília era três vezes e meio o que ganhávamos no Rio, mas ninguém quis vir. Eu vim para ficar dois anos. O único que topou vir comigo foi o Melatti. Viemos no mesmo voo. Carioca, ele não queria nem saber, nem imaginar como era Brasília ${ }^{1}$.

Os professores Roque Laraia e Júlio César Melatti são assim os pais refundadores das ciências sociais na UnB, responsáveis pela reestruturação desse novo período e encarregados das novas contratações:

Com o novo quadro docente foi possível criar, de imediato, o curso de graduação em ciências sociais que recebeu a adesão de muitos alunos que o aguardavam, enquanto faziam outros cursos (Laraia, 1995: 16).

Os professores pioneiros desse período são: Fernando Correia Dias, Maria Ignês Bastos Melo, Maria das Mercês Niquini Gomes, Élbio Gonzáles, Gláucio Ary Dilon Soares, Hélcio Ulhôa Saraiva, José Carlos Brand de Aleixo, Vânia Mara Franco Drumond. Posteriormente foram incorporados David Fleischer, Vilma Figueiredo e Barbara Freitag, esta por indicação de Florestan Fernandes. A partir de 1972, destaca-se o papel do professor Roberto Cardoso de Oliveira.

Em 1970, com o apoio da Fundação Ford, foi possível criar o mestrado em sociologia: "isso foi feito, paradoxalmente, em um momento em que outros centros de sociologia do país sofriam uma forte perseguição política" (Laraia, 1995: 16). O mestrado de sociologia, portanto, foi criado no âmbito do Departamento de Ciências Sociais, antes mesmo da criação do Departamento de Sociologia.

O mestrado disciplinar em sociologia não deixou de representar o sentido transformador de uma época, direcionado pela sensibilidade e responsabilidade de um grupo de professores levados a pensar, por um lado, "soluções" para o país, e, por outro, a constituir um território fértil à produção do conhecimento. Havia muito entusiasmo e excelência da docência na graduação e, por extensão, na pós-graduação, 
onde prevaleciam jovens plenos de expectativas e ideais. O papel do professor era o de semeador de ideias no processo de fecundação do conhecimento.

Na época, configurava-se uma dada resistência - tanto por parte de professores e estudantes, como por parte da administração dos departamentos - às pressões de órgãos externos [de fomento] nacionais e internacionais que almejavam definir um "perfil de produtividade" e de "competência" na pós-graduação, baseados em dados estatísticos. A resistência ocorreu não apenas como ação política, mas, sobretudo, para assegurar a autonomia e a liberdade de cátedra.

O fato de o mestrado em sociologia ter sido criado antes do Departamento de Sociologia possibilitou que as primeiras turmas do mestrado tivessem aulas com professores da Sociologia, da Antropologia e da Ciência Política. Por essa razão, também, muitos dos alunos selecionados foram arguidos por sociólogos, antropólogos e cientistas políticos. As primeiras seleções para o mestrado foram realizadas com a presença desses professores nos estados dos próprios candidatos.

\section{Tempo de buscas: \\ as temáticas dos cursos, os professores e os objetos de estudo}

O curso de pós-graduação em sociologia na UnB tornou-se atrativo para muitos estudantes pela novidade que representava Brasília à época, pelo quadro de professores contratados, sua competência, e pela própria temática do mestrado: sociologia do desenvolvimento. Essa temática possibilitava pensar o Brasil tanto em suas dinâmicas interiores particulares como nas relações de "dependência" com os chamados "países desenvolvidos". Dito de outro modo, esse era um campo de interesse da sociologia no Brasil, nos idos dos anos 1960-1970:

[...] Brasil [que] estava dividido não apenas economicamente entre os muitos desprovidos e os poucos privilegiados, mas demograficamente entre os habitantes dos espaços urbanos e os que lutavam pela permanência ou pela saída no e do mundo rural. As divisões brasileiras permaneceram em muitas frentes, exceto na demográfica. Mais de $80 \%$ da população opera hoje no universo de valores urbanos (Bomeny, 2008: 2).

Se, por um lado, a sociologia do desenvolvimento e a sociologia rural atraíam os estudantes, por outro, a sociologia política, a sociologia urbana e a sociologia da educação também constituíam demandas importantes, por permitirem problematizar as estruturas de poder vigentes na sociedade brasileira, a situação das elites, 
além de outros problemas sociais. De acordo com Darcy Ribeiro, as tensões sociais possibilitavam reatualizar seus significados:

\begin{abstract}
Nesta tarefa de desvendamento das causas ocultas e ocultadas de nosso atraso nacional é que temos sido mais coniventes. É gritante o descaso acadêmico pela elaboração e difusão de um discurso através do qual o nosso povo se explique e aceite. As classes dominantes dizem, com toda a altivez, que a culpa do atraso não é delas. Estaria no clima, na mistura de raças: tanto calor, tantos mulatos. Nada vale todos os saberes científicos que aí estão a dizerem há tantas décadas que nenhum fator natural, climático ou racial é explicativo do desempenho de um povo. Dentro da pupila de nossas classes patronais e patriciais continua persistente este olhar racista, raivoso, azedando a convivência entre os brasileiros (Ribeiro, 1986b: 10).
\end{abstract}

Relatos de alunos e pós-graduandos recompõem a memória dos primeiros anos do mestrado em sociologia na UnB. Lourdes M. Bandeira ingressou no mestrado em 1975, por meio de uma seleção realizada em São Paulo, cujo responsável foi o professor David Fleischer. Apresentou um projeto relacionado à sociologia da educação, que resultou em sua dissertação sobre o Serviço Nacional de Aprendizagem Profissional (Senac), instituição de educação profissional. Tinha concluído a graduação - bacharelado em ciências sociais pela Universidade Federal do Rio Grande do Sul - em dezembro de 1973. Maria Francisca Pinheiro Coelho ingressou no mesmo ano e foi selecionada em Fortaleza pelos professores Roque de Barros Laraia e Hélcio Ulhoua Saraiva. Seu ensaio na seleção intitulou-se "Tentativas de confronto entre modelos explicativos do desenvolvimento brasileiro", publicado um ano depois no primeiro número da Revista de Ciências Sociais, da universidade Federal do Ceará (Pinheiro, 1976).

A turma do mestrado em sociologia que entrou em 1975 tinha 15 alunos, a maior em relação às seleções anteriores. Lourdes Bandeira relembra o impacto que lhe causou o novo curso:

O momento de ingresso na UnB me causou certo "pânico". Em 1976, os muitos comentários sobre o reitor da época, Luís Carlos de Almeida Azevedo, o Capitão-de-Mar-e-Guerra, como era conhecido, traziam a imagem do olho panóptico de Foucault ao refletir o clima geral de perseguição e de ameaça nos corredores da universidade. Existia um sistema de estreito controle não apenas disciplinar, sobretudo acadêmico, em relação a alunos e professores (permanência, tempo, manifestações, notas, circulação, convivência frequente no campus etc. etc.), que gerava um pânico permanente. 
De acordo com Lourdes Bandeira, mesmo diante desse clima de insegurança, a convivência estudantil era extremamente cordial e afetiva. O coordenador do Programa de Pós-Graduação era então o professor Gláucio Ari Dillon Soares,

um professor forte, quase imponente, com formação quantitativa, nos Estados Unidos, rigoroso e atento. Nós, estudantes, não sabíamos muito como circular pelo campus com desenvoltura naqueles tempos tão difíceis.

Os pós-graduandos vinham de diferentes estados, uma vez que se tratava do momento de expansão dos cursos de pós-graduação, depois da reforma do ensino superior, ocorrida em 1968. Na Sociologia, relata Lourdes Bandeira, as matérias e os professores mais proeminentes na época eram: Vilma Figueiredo que ministrava Sociologia do desenvolvimento e Teoria sociológica; Maurício Vinhas de Queiroz que dava as disciplinas Movimentos messiânicos no campo, como o Contestado, em Santa Catarina, o Movimento operário e Estudos marxistas. "O professor era um homem forte e excêntrico, grande conhecedor da obra de Marx." O professor Gentil Dias ensinava Sociologia rural. O professor Fernando Correia Dias ministrava Sociologia brasileira e Sociologia urbana. A professora Barbara Freitag ensinava Teoria sociológica clássica.

Com a professora Barbara, sofríamos forte influência dos autores da escola de Frankfurt. Tínhamos de ler Habermas, Marcuse e Adorno, assim como estudamos em profundidade Antônio Gramsci. Eu mesma não tinha tido contato com os autores da Escola da Frankfurt, durante a graduação, na UFRGS, uma vez que o curso se voltava para os autores mais clássicos - Durkheim, Weber e Marx, conhecidos zombeteiramente como "os três porquinhos". A professora Barbara era ousada em seus cursos, pois como tinha uma circulação internacional, centrava os cursos também na análise marxista e fazia uso de $O$ Capital na edição consolidada em alemão, sem a ortodoxia que caracterizava as análises militantes à época. Também demonstrava sua ousadia em enfrentar o autoritarismo da reitoria, o que sempre fez com galhardia, até o dia em que "deixou" ou "teve de deixar" a UnB, no segundo semestre de 1977.

A professora Maria Helena Lerda ministrava Sociologia das migrações e, juntamente com Pedro Demo, respondia pelas disciplinas metodológicas, enquanto o professor David Fleischer oferecia os cursos de técnicas de pesquisa. O professor Lauro Campos, do Departamento de Economia, também ministrava disciplinas sobre a leitura de $O$ Capital. As metodologias compunham uma área de muita densidade em termos de carga horária, com excelentes professores. Somente nos anos de 1990 foi 
introduzido o curso de Teoria sociológica contemporânea, cuja primeira professora foi Vilma Figueiredo. Essa disciplina posteriormente passou a ser ministrada pela professora Mariza Veloso, por muitos semestres consecutivos.

Comparativamente com o de hoje, o curso de mestrado era estruturado em outras bases e tinha uma oferta maior nas disciplinas teóricas e obrigatórias. O período de tempo de realização do curso também era maior, podendo o/a aluno/a se formar em até oito semestres. A Coordenação de Aperfeiçoamento de Pessoal de Nível Superior (Capes), evidentemente, mantinha outra relação com os programas de pós-graduação, bem diferente da instrumentalização hoje vigente. No curso de graduação, por exemplo, era muito comum que os alunos concluíssem com dupla opção - sociologia e antropologia.

Em virtude de seu corpo docente, o Departamento de Sociologia se caracterizava pela densa carga de teoria. O uso da bibliografia era centrado nos estudos marxistas e no estruturalismo, seguindo um modelo que refletia a experiência europeia (marxista, sobretudo). Por outro lado, a presença de autores americanos, embora mais reduzida, também estava presente, sobretudo autores como Talcott Parsons e Robert Merton. Outros autores também eram estudados, como Karl Mannheim, Georg Simmel e Marcel Mauss.

Os professores da graduação, com poucas exceções, eram os mesmos da pós-graduação e introduziam os mesmos autores. Os autores brasileiros mais estudados eram Florestan Fernandes, Fernando Henrique Cardoso, Juarez Brandão Lopes, Costa Pinto e Octavio lanni. Querendo ou não, a USP continuava sendo a referência - o horizonte -, tanto no ensino da sociologia nacional como na pesquisa. Influências também emanavam do Centro Brasileiro de Análise e Planejamento (Cebrap).

Vale lembrar que o sistema de pós-graduação que estava sendo instalado resultava da Reforma Universitária do Ensino Superior, promulgada pela Lei n.ำ 5.540, de 1968. A reforma baseava-se no modelo americano, com a criação do sistema de disciplinas, departamentalização e divisão em semestres. Procurava-se construir os campi longe do centro dinâmico das cidades, para que não houvesse a mobilização de estudantes ou qualquer outro tipo de ajuntamento. Um dos mentores da reforma universitária foi o professor da UnB Milton Sucupira, eminente professor da Faculdade de Educação.

Tendo como referência a experiência da sociologia na UnB dos anos de 1970, podemos salientar como fatos institucionais, os seguintes: 
1. A preocupação com a institucionalização da sociologia enquanto disciplina acadêmico-científica. Nesse sentido, as escolas sociológicas mais presentes nesse processo de consolidação eram, prioritariamente, a marxista, e, secundariamente, as escolas durkheimiana e o funcionalismo americano. Esse ponto pode ser bem ilustrado pela síntese proposta por André Botelho, ao resumir o pensamento de Glaucia Villas Boas:

[...] deve ser explicitada uma distinção analítica fundamental que sustenta os argumentos sobre a sociologia brasileira da mudança social: a distinção entre "construção de nação" e "construção de sociedade". Para Glaucia Villas Boas, as interpretações de Gilberto Freyre e Euclides da Cunha, ao contrário da produção sociológica dos anos 1950, operam, tanto cognitiva, quanto politicamente a partir e dentro do paradigma da nação, da singularidade ontológica divisada nas origens, da particularidade que nos une e distingue dos "outros", o que lhes permite dar conta da construção de uma "identidade nacional" e de suas diferenças, mas não da construção de uma "sociedade moderna", da questão das desigualdades sociais que o paradigma universalista permite evidenciar e da sua mudança, mesmo que provocada. E é essa indistinção entre "nação" e "sociedade" que concorreria para a criação e manutenção do "mito" da ambiguidade do brasileiro, já que leva a que se confundam - nem sempre ingenuamente - valores de uma sociedade tradicional, do ponto de vista do paradigma sociológico e ethos brasileiro (Botelho, 2009: 5).

2. O estudo da sociologia francesa, alemã, americana e latino-americana. A França era uma referência como produtora de bibliografias. Depois vinham os autores Max Weber, Karl Mannheim, com a sociologia do conhecimento, e posteriormente Georg Simmel, com a sociologia urbana e a Escola de Chicago. Posteriormente, vêm autores como Pierre Bourdieu, com a teoria da reprodução (1975), que fez grande sucesso na academia, assim como Michel Foucault com Vigiar e punir. (1975), Microfísica do poder (1979).

3. O surgimento de departamentos, os quais tendiam a estar articulados aos cursos de graduação de suas respectivas disciplinas e aos cursos de pós-graduação.

4. A criação de cursos de pós-graduação e a organização de comunidades científicas especializadas, caracterizando a etapa da Big Science.

5. A fundação da comunidade acadêmico-científica com a importância dada ao modelo de interação vigente no estabelecimento do clima in- 
terno de comunidades científicas específicas e em suas possibilidades de interação com outras comunidades científicas (com padrões de estratificação, padrões normativos e padrões de comunicação).

A emergência da sociologia no Brasil tinha se dado sob a égide do paradigma estrutural-funcionalista, da consecução de um padrão de institucionalização e de prática do ensino e da pesquisa em sociologia, de modo similar ao ocorrido nos centros sociológicos dos países centrais, sobretudo França e Estados Unidos. A concepção e o fundamento dessa abordagem tiveram sua expressão na teoria da modernização e em sua análise do processo de transição da sociedade tradicional para a sociedade moderna.

As disciplinas na graduação e na pós-graduação em sociologia na Universidade de Brasília tinham forte embasamento nas teorias. Salienta a professora Mariza Veloso:

Os cursos de teoria sociológica, especialmente a sociologia clássica, sempre tiveram grande importância na graduação e na pós-graduação na UnB. Igualmente importantes eram as disciplinas relacionadas ao núcleo de métodos e técnicas de pesquisa.

No bojo da crise social e política vivenciada pelos países da América do Sul nas décadas de 1960 e 1970, com a instalação de regimes militares na região, verificou-se uma crise de retração da sociologia. Paradoxalmente, como forma de resistência, ocorreu uma diversificação da sociologia latino-americana, caracterizada pela crise institucional da sociologia provocada pela repressão política e cultural dos regimes militares. No interior da crise de hegemonia da chamada sociologia científica, deu-se a emergência de alternativas teóricas, como as chamadas sociologias nacionais, tal como a teoria da dependência e a da marginalidade social, tratadas por autores latinos, dentre os quais Anibal Quijano, Jorge Graciarena, Ruy Mauro Marini, Theotônio dos Santos, Vânia Bambirra. Grosso modo, essa conjuntura perdurou na sociologia brasileira do final dos anos 1960 até meados dos anos 1980.

Com a emergência do ciclo autoritário dos anos 1960-1970 - que coloca um fim às experiências democrático-desenvolvimentistas -, a questão educacional e científico-tecnológica adquiriu novos contornos. As políticas educacionais e científicas repressivas e recessivas dos governos autoritários levaram a uma quebra da autonomia universitária. Por sua vez, as cassações, prisões e diáspora intelectual-acadêmica restringiram as possibilidades de expansão do conhecimento e do ensino da sociologia.

Além das lutas estudantis, outras forças sociais atuantes contribuíram para o desgaste e o fim do regime militar no Brasil, entre elas as greves operárias do $A B C D$ 
paulista, da cidade de Contagem em Minas Gerais e o Movimento pela Anistia, que reivindicava a volta dos exilados e a liberdade dos presos políticos. O Movimento pela Anistia foi composto particularmente por mulheres, esposas, mães, familiares dos exilados e presos políticos. O ponto alto das mobilizações pela volta da democracia foi o Movimentos das Diretas-Já!, em 1984, quando ocorreram grandes mobilizações populares, envolvendo milhões de pessoas nas principais capitais e cidades do país.

No meio acadêmico, foi criada a Associação Nacional de Pós-Graduação em Ciências Sociais (Anpocs), em 1978, e reativada a Sociedade Brasileira de Sociologia (SBS), fundada em 1948. Emergiram também nesse momento as agências internacionais de fomento, como a Fundação Ford, que passou a conceder bolsas e a financiar programas de inclusão social - mulheres/gênero, negros e índios - que, de alguma maneira, acabaram por influenciar o rumo e os avanços de análises sociológicas. No campo do ativismo político, surgiram novos sujeitos e consolidaram-se as lutas por identidades, emergindo o movimento de mulheres, de negros, sobretudo, com novas temáticas que iriam se afirmar, apesar das resistências institucionais. As lutas indenitárias passaram a constituir novos temas da sociologia.

\section{Os ventos de Brasília,}

\section{o ethos da sociologia e as gerações}

A sociologia da UnB tem algo em particular que lhe acompanha desde sua implantação na instituição: em todos os relatos sobre as características do Departamento de Sociologia, nos relatórios da Capes ou nas descrições sobre o perfil do corpo docente, são ressaltadas como qualidades a heterogeneidade do lugar de origem dos professores e a diversidade de sua formação, com ênfase na pós-graduação em diferentes países. Essa diversidade proporcionaria uma pluralidade de abordagens, a abertura para o diálogo e o pensamento crítico. Favorece também a multiplicidade de perspectivas analíticas e de objetos de estudo, que impulsionam a produção de um conhecimento sociológico apoiado em sólidas bases epistemológicas e metodológicas.

A heterogeneidade dos lugares de origem e a diversidade de formação da pós-graduação do corpo docente do Departamento de Sociologia da UnB aproximam o ethos do sociólogo da UnB ao do tipo social do estrangeiro construído por Georg Simmel: como o do habitante móvel, aquele que não nasceu aqui, mas que veio para ficar. Esse habitante móvel consegue olhar com mais distanciamento o seu redor e o outro. O morador de Brasília já tem essa característica naturalmente, mas, para o corpo docente da UnB, esse traço geral dos que vivem aqui se apresenta 
como uma qualidade a mais, um atributo da profissão, definido pela capacidade de se aproximar e se distanciar de seus objetos de estudo.

A objetividade é a lição sociológica maior do ensaio "O estrangeiro", de Georg Simmel (1983), visto não no sentido do viajante que não se fixa em nenhum lugar, mas da pessoa que chega hoje e amanhã fica. Do estrangeiro como forma específica de interação social. Na reflexão do autor, a objetividade se define como a liberdade, o valor maior na produção científica, por seu compromisso intrínseco com a verdade:

O indivíduo objetivo não está amarrado a nenhum compromisso que poderia prejudicar sua percepção, entendimento e avaliação do que é dado (Simmel, 1983: 185).

A proximidade e a distância se apresentam assim como forma de relação social comum a todas as pessoas, mas no tipo social do estrangeiro ganham o traço particular da objetividade.

O perfil do corpo docente da Sociologia da UnB, sua densa e sólida formação acadêmica, favorece a postura reflexiva e a convivência entre diferentes escolas e enfoques sociológicos. Pelo menos é o que se percebe na geração fundadora do Departamento de Sociologia e que se deseja como legado para as novas gerações. A Escola Sociológica de Brasília, se assim pode-se chamá-la, não tem laços estabelecidos com determinadas tendências nem se submete a componentes ou a tendências peculiares de grupos. Está sempre aberta a novos olhares e perspectivas, sem abrir mão da base factual, o fundamento empírico das ciências sociais. Em Brasília, a produção da sociologia tem uma tendência à objetividade e à diversidade. Objetividade que não envolve simplesmente passividade e afastamento, mas uma estrutura particular composta de distância e proximidade.

Essa imagem um tanto idealizada do habitante de Brasília - que não tem raízes em uma tradição - é uma visão aproximada do traço peculiar da produção das ciências sociais na UnB. Trata-se de um conhecimento que se caracteriza pela multiplicidade de temas e abordagens, portanto avesso, nas origens, às ortodoxias, e sempre aberto a rever princípios e orientações.

O perfil do estrangeiro foi o papel atribuído ao professor Roque de Barros Laraia ao desembarcar em Brasília, em 1969. Em suas palavras, foi-Ihe pedido para "refazer o desfeito". A proporção de proximidade e distância deu àqueles professores pioneiros e à geração formada por eles o traço das ciências sociais produzidas na Universidade de Brasília. Proporcionou-Ihes também a característica do usuário do 
livre pensar, que se expressa na busca do desvendamento sociológico da realidade, sem preconceitos nem juízo de valor:

O cientista social na UnB é o estrangeiro que não sabe se fica, mas nunca vai embora, e essa condição lhe possibilita desvendar Brasília (Coelho, 2010: 62).

Quando a geração de pós-graduandos da década de 1970 ingressou na UnB, além da exigência de uma formação teórica sólida com a leitura dos clássicos e contemporâneos da sociologia, contribuiu muito para a definição dos temas de estudos da época a conjuntura política do país: o ressurgimento das mobilizações contra a ditadura militar, o movimento da anistia em 1979, marcadamente feminino, o movimento operário, com as greves em ascensão. As questões da sociologia se relacionavam aos temas de mudança social. Os trabalhos produzidos naquele momento trazem a marca daquele período político brasileiro que prenunciava o fim do regime militar.

Comparações entre o passado e o presente são importantes, mas não esgotam as particularidades e possibilidades de cada momento. As ações individuais e coletivas não se conformam completamente às influências e circunstâncias de um tempo nem são por ele enquadradas. Embora as ideias de uma época influenciem a produção do conhecimento sociológico e sejam motivações para a ação, há sempre a possibilidade do inusitado e do surpreendente.

As ideias conformam um tempo, mas a prevenção contra qualquer tipo de determinismo evita o enquadramento da produção sociológica. Nas palavras de Mannheim (1951), quando se fala de geração se refere sempre ao espírito de um tempo, a um sentido coletivo, mas existe sempre a possibilidade do "contemporâneo do não contemporâneo", como forma de vivência no presente de um passado que se foi. Mesmo em uma geração que compartilha um destino coletivo existem diferentes unidades de geração. Pode-se também prever no presente tendências do futuro, como a vanguarda de um tempo.

Nessa relação entre passado e presente, pode-se avaliar que certos valores do passado são datados, mas que outros podem iluminar práticas no presente. O depoimento, em 1995, de um jovem professor do Departamento de Sociologia, por ocasião das comemorações dos 25 anos do programa de pós-graduação em sociologia, elucida bem um valor do passado que se quer preservar no presente: o do convívio entre gerações. 
Sua análise representa uma introjeção do sentido institucional e coletivo da geração fundadora do Departamento de Sociologia e de seu papel para as gerações mais jovens, como exemplo de convivência e ensinamento. O professor falava do quanto aprendia com a convivência entre os pares. Seu depoimento se constitui em uma lição para os dias de hoje. Ao se referir ao convívio das gerações, o professor Eurico Cursino dos Santos, jovem professor na época, tinha como foco as reuniões do Departamento:

Nelas, as paixões e as vaidades encontram-se com as consequências dos compromissos que cada um assume com os valores da instituição científica. E as figuras de mestres estão sempre lá, lembrando-nos da possibilidade de atribuirmos um sentido honesto às sequelas de nossas opções. Ainda mais, advertindo-nos da oportunidade de fazermos isso em grupo, respeitando e tolerando o outro, como rezam os melhores valores, para que a relação entre o indivíduo e a instituição possa modelar a ambos com o mínimo de conflitos (Santos, 1995, p. 104-105).

Pode-se argumentar que, na história do Departamento de Sociologia da UnB, apesar dos conflitos inerentes a toda instituição, houve sempre uma convivência respeitável e dialógica entre os pares, independente de orientações teóricas e opções políticas, principalmente dos mais antigos em relação aos novos. Do mesmo modo, a convivência entre professores e alunos e entre os alunos sempre foi intensa e amistosa. Digno de registro era a frequência de alunos das ciências sociais na Biblioteca Central, onde se encontravam, estudavam juntos e compartilhavam ideias. O espírito de solidariedade era um traço característico de professores e alunos de ciências sociais. Os professores frequentavam assiduamente o Departamento, ocupando suas salas para estudar, trabalhar e atender alunos. A presença de todos em um efetivo intercâmbio favorecia trocas afetivas e acadêmicas entre os colegas.

Como foi mencionado, a história das ideias fundadoras da UnB coincidem com as da construção de Brasília e com o ethos das ciências sociais produzidas na instituição. Além do projeto acadêmico de autonomia, o concreto da UnB compõe também com a arquitetura modernista de Oscar Niemeyer, integra o espaço urbano, a paisagem da Asa Norte e tem como vista o Lago Paranoá, cuja existência possibilita a vivência nesse lugar do Planalto Central: "Ainda ontem eu e a lua tomávamos banho no lago", cantou em poesia o Lago Paranoá o poeta cearense Augusto Pontes, formado em jornalismo pela UnB, onde foi professor da comunicação. 


\section{Referências}

BOMENY, Helena. Sociologia como missão: fazer ciência fazendo história? Rio de Janeiro: CPDOC, 2008. 9f. Resenha de: VILLAS BOAS, Glaucia. Mudança provocada: passado e futuro no pensamento sociológico brasileiro. Rio de Janeiro: Editora FGV, 2006. Disponível em: <http://www.cpdoc.fgv.br>.

BOTELHO, André. Universal e particular na sociologia brasileira da mudança social. Sociologias, n. 21, Porto Alegre Jan.-Jun. 2009.

COELHO, Maria Francisca Pinheiro. Brasília e a geração UnB nas ciências sociais. Revista Darcy, v. 4, Universidade de Brasília, Ago.-Set. 2010.

COSTA, Ana Maria; SIQUEIRA, Deis; BANDEIRA, Lourdes. UnB: Tempo e espaço do resgate do naufrágio e do sonho. Texto premiado e publicado nos Anais dos 30 anos comemorativos da UnB. Brasília, Out. 1992.

FOULCAULT, Michel. Vigiar e punir. O nascimento da prisão. Lisboa: Edições 70, 1975.

Microfísica do poder. São Paulo: Paz e Terra, 1979.

GRUPIONI, Luís Donisete B.; GRUPIONI, Maria Denise F. Depoimento de Darcy Ribeiro. BIB/Anpocs, n. 44, p.3-135, Rio de Janeiro, Jul.-Dez. 1977.

LARAIA, Roque de Barros. Entrevista. Concedida a COELHO, Maria Francisca Pinheiro. Brasília, jun., 2015.

—. 25 anos: uma história. Sociedade e Estado, v. 20, p. 17-18, 1995.

MANNHEIM, Karl. O problema das gerações. In: —— Sociologia do conhecimento. v. 2, p. 115-174. Porto: RÉS-Editora, 1951.

PINHEIRO, Maria Francisca Sales. Tentativas de confronto entre modelos explicativos de desenvolvimento. Revista de Ciências Sociais, v. 1, p. 30-38, Fortaleza, 1976.

RAMAIANA RIBEIRO, Antonio. UnB 1977: o início do fim. Brasília: Paralelo 15, 2009. RIBEIRO, Darcy. UnB, invenção e descaminho. Rio de Janeiro: Avenir, 1986a.

—_. Universidade para quê? "Série UnB". Brasília: Editora UnB, 1986b.

SANTOS, Eurico A. G. C. A sociologia e seus mestres. Sociedade e Estado. Edição comemorativa dos 25 anos da Pós-Graduação em Sociologia. v. 20, p. 103-105, 1995. 
SIMMEL, Georg. O estrangeiro. In: MORAES FILHO, Evaristo de (Org.). Sociologia, p. 182-188. São Paulo: Ática, 1983.

VILLAS BOAS, Glaucia. Mudança provocada: passado e futuro no pensamento sociológico brasileiro. Rio de Janeiro: Editora FGV, 2006. 